\title{
Role of MMP-2 (-1306 C/T) Polymorphism in Pituitary Adenoma
}

\author{
Brigita Glebauskiene, ${ }^{1}$ Rasa Liutkeviciene, ${ }^{1,2}$ Alvita Vilkeviciute, ${ }^{2}$ Loresa Kriauciuniene, ${ }^{1,2}$ \\ Giedrimantas Bernotas, ${ }^{2,3}$ Arimantas Tamasauskas, ${ }^{2,3}$ and Dalia Zaliuniene ${ }^{1}$ \\ ${ }^{1}$ Medical Academy, Department of Ophthalmology, Lithuanian University of Health Sciences, Eiveniu 2, 50009 Kaunas, Lithuania \\ ${ }^{2}$ Neuroscience Institute, Medical Academy, Lithuanian University of Health Sciences, Eiveniu 2, 50009 Kaunas, Lithuania \\ ${ }^{3}$ Medical Academy, Department of Neurosurgery, Lithuanian University of Health Sciences, Eiveniu 2, 50009 Kaunas, Lithuania
}

Correspondence should be addressed to Brigita Glebauskiene; bglebauskiene@gmail.com

Received 7 December 2015; Revised 10 February 2016; Accepted 11 February 2016

Academic Editor: Cornelis F. Sier

\begin{abstract}
Copyright (C) 2016 Brigita Glebauskiene et al. This is an open access article distributed under the Creative Commons Attribution License, which permits unrestricted use, distribution, and reproduction in any medium, provided the original work is properly cited.

Purpose. To determine if the frequency of the genotype of MMP-2 (-1306 C/T) Rs243865 has an influence on the development of pituitary adenoma (PA). Methods. The study enrolled $n=84$ patients with PA and a random sample of the population $n=318$ (reference group). The genotyping test of $M M P-2(-1306 \mathrm{C} / \mathrm{T})$ was carried out using the real-time polymerase chain reaction method. Results. Analysis of $M M P-2(-1306 C / T)$ gene polymorphism has not revealed any differences in the genotype $(C / C, C / T$, and $T / T)$ distribution between the PA patients and the reference group (as follows: 50\%, 44\%, and 6\% versus 59.75\%, 33.96\%, and 6.29\%). MMP-2 (-1306) C/C genotype was rarely observed in noninvasive PA compared to healthy controls: $35.1 \%$ versus $59.75 \% ; p=0.0049$, as well C/C genotype being more frequently detected in nonrecurrence PA compared to healthy controls: $46.5 \%$ versus $59.75 \%$; $p=0.0468 . M M P-2(-1306) C / T$ genotype was more frequently present in PA females compared to healthy controls females: $49.1 \%$ versus $33.66 \% ; p=0.041$. Conclusion. Patients with noninvasive and nonrecurrence pituitary adenoma were the carriers of the $\mathrm{C} / \mathrm{C}$ genotype significantly more frequently than their control counterparts and the $\mathrm{C} / \mathrm{T}$ genotype in females was more frequent.
\end{abstract}

\section{Introduction}

Pituitary adenoma (PA) is a common benign monoclonal neoplasm accounting for approximately $15 \%$ to $20 \%$ of primary intracranial tumours [1]. Ezzat et al. [2] reported the estimated prevalence rates of pituitary adenomas to be $14.4 \%$ to $22.5 \%$ in pooled autopsy and radiological series, respectively. The pituitary gland is localized in a dural bag attached to the inferior aspect of the diaphragm of the sella and surrounded by venous spaces that correspond laterally to the cavernous sinuses [3]. PA may grow large and extend into the surrounding structures resulting in neurological complications including visual impairment. $6 \%$ to $10 \%$ of pituitary adenomas involve the cavernous sinus [4-9]. PA is a disease of multifactorial etiology, the occurrence of which is influenced by alterations in hormonal regulation and hormone receptors, dysregulated growth factors and alterations in their receptors, abnormalities in signaling proteins that transduce the signals of these stimuli, and changes in cell-cycle regulators. In addition, the neoplastic process is associated with altered cell-stromal interactions that have a role in the morphogenesis of pituitary tumours [10]. Recently, great attention in the PA pathogenesis has been drawn to the search of new epigenetic and genetic factors. To invade, tumour cells must undergo several changes in molecular pathways in accordance with invasion-associated cellular activities, namely, cell-cell adhesion, cell-matrix adhesion and ectopic survival, migration, and proteolysis [11]. Matrix metalloproteinases (MMPs), a family of zinc-dependent endopeptidases, also called matrixins, play an important role in the process of degradation of the extracellular matrix (ECM) and basement membrane (BM) in relation to tumour invasiveness, metastasis, and angiogenesis [12-18]. Many factors might induce MMPs production: cytokines, growth factors, physical stress, cell-extracellular matrix, and cell-cell interaction [19].

MMP-2 is a member of the MMP family and is capable of hydrolyzing type IV collagen, which is the main component of the BM $[13,15]$. Several studies have shown that MMP-2 plays an important role not only in tumour 
invasion and metastasis, but also in cancer development $[20,21]$.

Numerous studies have shown that MMP-2 is overexpressed in various human tumours, including breast cancer [22-27], lung cancer [28], colorectal tumours [29], pancreatic carcinoma [30], and gastric and esophageal cancers [31-35]. Some studies have also showed the expression of MMP2 in human gliomas [36-38]. There are not many studies analyzing MMP-2 expression in PA $[5,39,40]$ and to the best of our knowledge there are no studies that have examined the MMP2 $-1306 \mathrm{C} / \mathrm{T}$ polymorphism in patients with PA.

MMP polymorphisms can be caused by nucleotide changes within the promoter region by insertions, substitutions, or microsatellite instability [41]. Price et al. [42] reported a single nucleotide polymorphism in the promoter of the MMP2 gene $(-1306 \mathrm{C} / \mathrm{T})$. $-1306 \mathrm{C} \rightarrow \mathrm{T}$ transition is located in a core recognition sequence of Sp1 (CCACC box), which abolishes the Spl-binding site and consequently diminishes promoter activity. Another $\mathrm{C}$ to $\mathrm{T}$ transition located at nucleotide -735 in the promoter region of $M M P$ 2 has been identified [43].

Numerous studies have been carried out to look for the possible association between the MMP2 -1306 C>T polymorphism and risk of human cancers (colorectal, breast, gastric, esophageal, prostate, lung, and oral cancer) (reviewed in $[44,45])$.

To our knowledge, no studies have investigated the association between the $M M P-2(-1306 \mathrm{C} / \mathrm{T})$ gene polymorphism and PA development. Therefore, the aim of this study was to determine the association between the MMP-2 (-1306 C/T) gene polymorphism and the development of PA.

\section{Materials and Methods}

Permission (Number P2-9/2003) to undertake the study was obtained from the Kaunas Regional Biomedical Research Ethics Committee. The study was conducted in the Departments of Ophthalmology and Neurosurgery, Lithuanian Health Sciences University Hospital.

Study participants comprised 84 subjects with a diagnosis of pituitary adenoma and 318 persons from the reference group.

Reference Group Formation. The reference group involved 318 subjects according to their age and gender, considering the pituitary adenoma group structure. It was constructed from the following:

(1) A random sample of the Kaunas population aged 4574 years collected within the international HAPPIE (Health, Alcohol and Psychosocial Factors in Eastern Europe) project (1) by the Laboratory of Population Research at the Institute of Cardiology of the Lithuanian University of Health Sciences (LUHS).

(2) A random sample of the Lithuanian population aged 25-65 years collected within the international CINDI (Countrywide Integrated Non-Communicable Disease Intervention) project (2) by the Laboratory of
TABLE 1: Demographic characteristics of patients with pituitary adenoma (PA) and reference group subjects.

\begin{tabular}{lccc}
\hline Group & $N$ & Age, year (min./max. median) & Males, $n(\%)$ \\
\hline PA & 84 & $19 / 87 / 52.5$ & $29(34.5)$ \\
Reference & 318 & $25 / 87 / 51$ & $113(35.5)$ \\
$p$ value & - & 0.88 & 0.86 \\
\hline
\end{tabular}

Preventive Medicine at the Institute for Biomedical Research of the LUHS.

(3) A random sample of the Kaunas population older than 65 years collected within the "Kaunas Healthy Ageing Study" by the Geriatric Clinic and Laboratory of Molecular Cardiology, Institute of Cardiology of the LUHS (3).

The reference group was created by taking into consideration the distribution of age and gender in the pituitary adenoma group. Therefore, the medians of the patient age of the reference group and the pituitary group did not differ statistically significantly $(p<0.05)$.

Demographic data of the study subjects are presented in Table 1.

The inclusion criteria were as follows: (1) determined and confirmed PA via MRI; (2) patient's general good condition; (3) patient's consent to take part in the study; (4) age $\geq 18$ years, (5) no other brain or other localization tumours.

2.1. Radiological Evaluation. All pituitary adenomas were analyzed based on MR imaging findings. The suprasellar extension and sphenoid sinus invasion by PAs were classified according to Hardy classification, modified by Wilson [46]. The degree of suprasellar and parasellar extension was graded as stages A-E. The degree of sellar floor erosion was graded as grades I-IV. Grades I-II mean that sellar floor is intact and was considered as noninvasive PA, grade III shows localized sellar perforation, and grade IV shows diffuse destruction of sellar floor which is the sign of invasive PA. Knosp classification system was used to quantify the invasion of the cavernous sinus. Grade 0: no involvement of cavernous sinus represents the normal condition; grades 1 and 2: the tumour pushes into the medial wall of the cavernous sinus but does not go beyond a hypothetical line extending between the centres of the two segments of the internal carotid artery (grade 1) or it goes beyond such a line, but without passing a line tangent to the lateral margins of the artery itself (grade 2); grade 3: the tumour extends laterally to the internal carotid artery within the cavernous sinus; grade 4: total encasement of the intracavernous carotid artery [47]. According to Knosp classification, only grades 3 and 4 pituitary tumours were considered to be invasive.

2.2. DNA Extraction and Genotyping. The DNA extraction and analysis of the gene polymorphism of MMPs were carried out at the Laboratory of Molecular Cardiology at the Institute of Cardiology of the LUHS for control group and at the Laboratory of Ophthalmology at the Institute of Neuroscience of the LUHS for the PA patient group. The DNA was extracted from the venous blood of patients 
TABLE 2: Frequency of $M M P-2(-1306 \mathrm{C} / \mathrm{T})$ genotype in the patients with pituitary adenoma (PA) and in the control group.

\begin{tabular}{|c|c|c|c|c|c|c|}
\hline \multirow[b]{2}{*}{ Gene marker } & \multirow[b]{2}{*}{ Genotype/allele } & \multicolumn{5}{|c|}{ Frequency (\%) } \\
\hline & & $\begin{array}{c}\text { Control group } \\
n(\%) \\
(n=318)\end{array}$ & $\begin{array}{c}p \\
\text { HWE }\end{array}$ & $\begin{array}{c}\text { PA group } \\
n(\%) \\
(n=84)\end{array}$ & $\begin{array}{c}p \\
\text { HWE }\end{array}$ & $p$ value \\
\hline \multirow{8}{*}{$\begin{array}{l}M M P-2 \\
(-1306) \\
R s 243865\end{array}$} & Genotype & & \multirow{8}{*}{0.383} & & \multirow{8}{*}{0.390} & \multirow{8}{*}{$\begin{aligned} \chi^{2} & =2.980 \\
p & =0.225\end{aligned}$} \\
\hline & $\mathrm{C} / \mathrm{C}$ & $190(59.75)$ & & $42(50.00)$ & & \\
\hline & $\mathrm{C} / \mathrm{T}$ & $108(33.96)$ & & $37(44.00)$ & & \\
\hline & $\mathrm{T} / \mathrm{T}$ & $20(6.29)$ & & $5(6.00)$ & & \\
\hline & Total & $318(100)$ & & $84(100)$ & & \\
\hline & Allele & & & & & \\
\hline & $\mathrm{C}$ & 0.767 & & 0.720 & & \\
\hline & $\mathrm{T}$ & 0.233 & & 0.280 & & \\
\hline
\end{tabular}

MMP: matrix metalloproteinase; $p$ value: significance level (alfa $=0.05)$; $p$-value HWE: significance level (alfa $=0.05)$ by Hardy-Weinberg equilibrium.

using the Genomic DNA Purification Kit (Thermo Fisher Scientific) according to the recommendations of the manufacturer or the silica gel column method utilizing the genomic DNA extraction kit SorpoClean ${ }^{\mathrm{TM}}$ Genomic DNA Extraction Module (SORPO Diagnostics) according to the recommendations of the manufacturer.

The genotyping test of MMP-2 (-1306 C/T) was carried out using the real-time polymerase chain reaction (PCR) method. Applied Biosystem (USA) kits were used for the genotyping of MMP-2 (-1306 C/T) (rs243865). To ensure internal control, 20 samples were sequenced at the Sequencing Center of the Institute of Biotechnology, and the received results confirmed the reiteration and precision of the data. The genotyping was performed using the HT 7900 realtime PCR quantification system (Applied Biosystems, USA). The real-time PCR reagents $\left(2 \mathrm{x}\right.$ Maxima $^{\mathrm{TM}}$ Probe/ROX qPCR Master mix buffer, fluorescent dye labeled markers, sterile $\mathrm{ddH} 2 \mathrm{O}$ ) were taken out from an environment of $-20^{\circ} \mathrm{C}$ and were thawed at room temperature. The thawed reagents were centrifuged $(10,000 \mathrm{rpm})$ and stored in an ice tub. An appropriate real-time PCR mixture of MMP-2 (-1306 C/T) was prepared for determining single nucleotide polymorphism (SNP).

$9 \mu \mathrm{L}$ of the PCR reaction mixture was poured into each well of the microtiter plate with 96 wells and then $1 \mu \mathrm{L}$ of matrix DNA of the samples $(\sim 10 \mathrm{ng})$ and $1 \mu \mathrm{L}$ of negative control $(-\mathrm{K})$ were added. An optic film was pasted on the microtiter with 96 wells and the microtiter was centrifuged for 15 seconds at 10,000 rpm.

During the genotyping the following real-time PCR programs were used: Allelic Discrimination and Absolute quantification. Then, the work was continued following the manual provided by the manufacturer (http://www.appliedbiosystems.com/ Allelic Discrimination Getting Started Guide). After that, the Allelic Discrimination program was completed, the genotyping results were received. The program determined the individual genotypes according to the fluorescence intensity rate of different detectors. A molecular marker labeled with VIC fluorescent dye or Yakima Yellow was chosen for the $x$ axis and a molecular marker labeled with FAM fluorescent dye was selected for the $y$-axis.
2.3. Statistical Analysis. Statistical analysis was performed using the SPSS/W 20.0 software (Statistical Package for the Social Sciences for Windows, Inc., Chicago, IL, USA). The data are presented as minimum, maximum, and median. The frequencies of genotypes (in percentage) are presented in Table 2. Hardy-Weinberg analysis was performed to compare the observed and expected MMP genotype frequencies using the $\chi^{2}$ test for all groups. The distribution of the MMPs (SNP) in the PA and control groups was compared using the $\chi^{2}$ test or Fisher exact test. Binomial logistic regression analysis was performed to estimate the impact of genotypes on PA development. Odds ratios (OR) and 95\% confidence intervals are presented. The selection of the best genetic model was based on the Akaike Information Criterion; therefore, the best genetic models were those with the lowest Akaike Information Criterion values. Differences were considered statistically significant when $p<0.05$.

\section{Results}

The genotyping of $M M P-2(-1306) C / T$ was performed in patients with PA and in the control group subjects (Table 2). The distribution of the analyzed MMP genotypes and allele frequencies in patients with $\mathrm{PA}$ and in the control group matched the Hardy-Weinberg equilibrium. MMP2 (-1306) $C / T$ gene polymorphism analysis in the overall group has not revealed any differences in the genotypes distribution between patients with PA and control group patients (Table 2).

MMP-2 (-1306) C/T gene polymorphism analysis in males and females with PA has not revealed any statistical significant differences in the genotype $(C / C, C / T$ and $T / T$ ) distribution (as follows: $45.5 \%, 49.1 \%$, and $5.5 \%$ versus $58.6 \%, 34.5 \%$, and $6.9 \%$ ) (Table 3). When comparing MMP2 genotype distribution in healthy females and females with $\mathrm{PA}$ we have revealed significant differences. $M M P$ 2 (-1306) $C / T$ genotype was more frequently present in PA females compared to healthy controls females: $49.1 \%$ versus $33.66 \% ; p=0.041 . M M P-2(-1306) \mathrm{C} / \mathrm{C}$ and $\mathrm{C} / \mathrm{T}$ genotypes have not revealed any statistically significant differences when healthy females and females with PA were compared: $M M P-2$ (-1306) C/C genotype 59.02\% versus 
TABLE 3: Frequency of MMP-2 (-1306 C/T) genotype in the patients with pituitary adenoma (PA) and in the control group by gender.

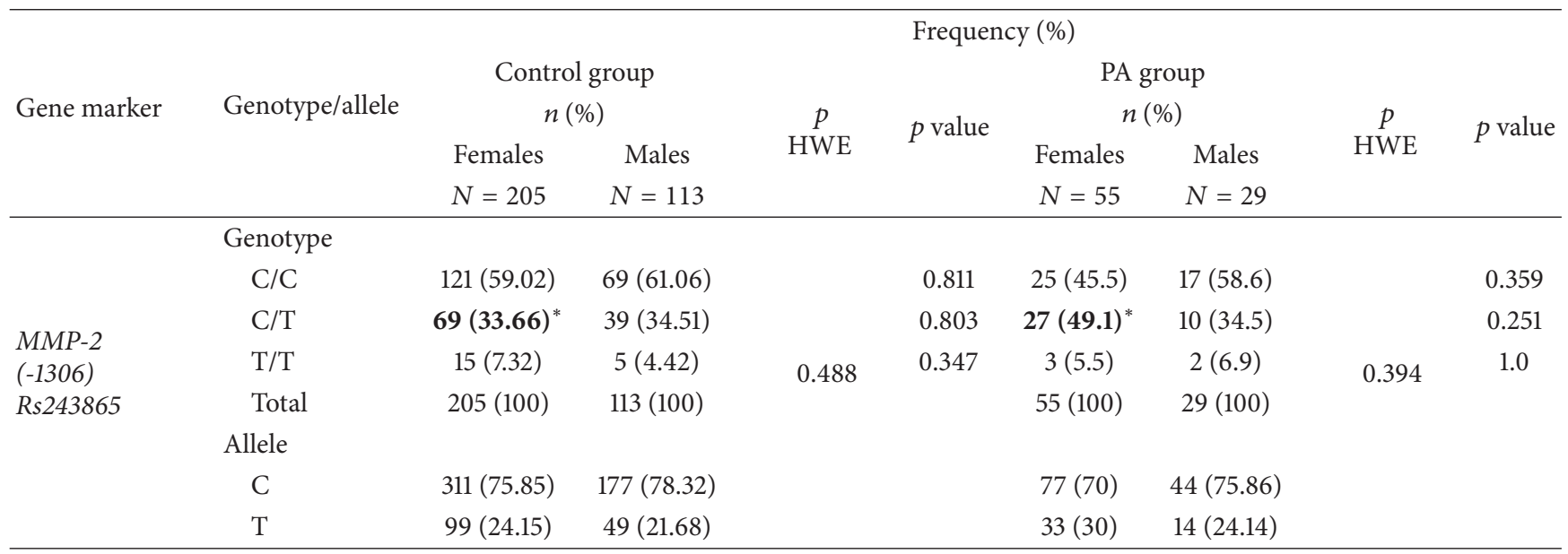

${ }^{*} p=0.0412$.

MMP: matrix metalloproteinase; $p$ value: significance level $($ alfa $=0.05)$; $p$-value HWE: significance level $($ alfa $=0.05)$ by Hardy-Weinberg equilibrium.

TABLE 4: Binomial logistic regression analysis in the patients with pituitary adenoma (PA) and in the control group.

\begin{tabular}{|c|c|c|c|c|}
\hline Model & Genotype & OR (CI 95\%) & $p$ value & AIC \\
\hline \multirow{3}{*}{ Codominant } & $\mathrm{T} / \mathrm{T}$ & 1 & & 415.177 \\
\hline & $\mathrm{T} / \mathrm{C}$ & $0.645(0.391-1.065)$ & 0.087 & \\
\hline & $\mathrm{C} / \mathrm{C}$ & $0.884(0.314-2.490)$ & 0.816 & \\
\hline \multirow{2}{*}{ Dominant } & $\mathrm{CC}$ & 1 & & 413.540 \\
\hline & $\mathrm{T} / \mathrm{C}+\mathrm{T} / \mathrm{T}$ & $0.647(0.416-1.092)$ & 0.109 & \\
\hline \multirow{2}{*}{ Recessive } & $\mathrm{C} / \mathrm{C}+\mathrm{C} / \mathrm{T}$ & 1 & & 416.093 \\
\hline & $\mathrm{T} / \mathrm{T}$ & $1.060(0.386-2.914)$ & 0.909 & \\
\hline \multirow{2}{*}{ Overdominant } & $\mathrm{T} / \mathrm{T}+\mathrm{C} / \mathrm{C}$ & 1 & & 413.231 \\
\hline & $\mathrm{C} / \mathrm{T}$ & $0.653(0.400-1.066)$ & 0.088 & \\
\hline Additive & $\mathrm{T}$ allele & $0.784(0.535-1.148)$ & 0.211 & 414.568 \\
\hline
\end{tabular}

$45.5 \% ; p=0.09 ;$ and $\mathrm{T} / \mathrm{T}$ genotype $15 \%$ versus $3 \%$, $p=0.772$.

Binomial logistic regression analysis in the patients with PA and in the control group was performed (Table 4). This analysis revealed that there were no statistically significant variables in the models of the patients with PA and in the control group.

Binomial logistic regression analysis in the patients with PA and in the control group by gender was performed (Table 4). There were no statistically significant variables in the models of the pituitary adenoma and control groups. Binomial logistic regression analysis in the patients with PA and in the control group by gender was performed as well (Table 5). There were no statistically significant variables in the models of males. In females this analysis revealed that the codominant $(p$ value $=0.043)$ and overdominant $(p$ value $=$ $0.037)$ variables were statistically significant.

MMP-2 (-1306) C/C genotype was rarely observed in noninvasive PA compared to healthy controls: $35.1 \%$ versus $59.75 \%$; $p=0.0049$, as well $\mathrm{C} / \mathrm{C}$ genotype being more frequently detected in nonrecurrence PA compared to healthy controls: $46.5 \%$ versus 59.75\%; $p=0.0468$ (Tables 6 and 7). These results could be explained by increased expression of $\mathrm{C} / \mathrm{C}$ genotype.
Binomial logistic regression analysis in noninvasive PA and in the control group was performed (Table 8). In noninvasive PA group this analysis revealed that the codominant $(p$ value $=0.003)$, dominant $(p$ value $=0.005)$, overdominant $(p$ value $=0.003)$, and additive $(p$ value $=0.028)$ variables were statistically significant. Binomial logistic regression analysis in the patients with nonrecurrence PA and in the control group was performed as well (Table 8 ). In nonrecurrence PA group this analysis revealed that the codominant ( $p$ value $=$ $0.039)$, dominant $(p$ value $=0.042)$, and overdominant $(p$ value $=0.049$ ) variables were statistically significant.

\section{Discussion}

Pituitary tumours are benign but do not uncommonly invade locally into adjacent tissues such as the cavernous sinus and dura. Early prediction of which pituitary tumours will recur and/or exhibit an invasive phenotype remains difficult despite the introduction of several tissue-based molecular markers [48].

The importance of $M M P-2$ (-1306) gene polymorphism in the susceptibility of various tumours has been shown in numerous studies [47-50]. In addition, MMP-2 has been shown to be overexpressed in $\mathrm{PA}[5,39,40]$. On the 
TABLE 5: Binomial logistic regression analysis in pituitary adenoma (PA) and the control women by gender.

\begin{tabular}{|c|c|c|c|c|}
\hline Model & Genotype & OR (CI 95\%) & $p$ value & AIC \\
\hline \multicolumn{5}{|l|}{ Males } \\
\hline \multirow{3}{*}{ Codominant } & CC & 1 & & 149.476 \\
\hline & $\mathrm{CT}$ & $0.961(0.401-2.303)$ & 0.929 & \\
\hline & $\mathrm{TT}$ & $0.616(0.110-3.452)$ & 0.582 & \\
\hline \multirow{2}{*}{ Dominant } & $\mathrm{CC}$ & 1 & & 147.705 \\
\hline & $\mathrm{T} / \mathrm{C}+\mathrm{T} / \mathrm{T}$ & $0.903(0.394-2.072)$ & 0.810 & \\
\hline \multirow{2}{*}{ Recessive } & $\mathrm{C} / \mathrm{C}+\mathrm{C} / \mathrm{T}$ & 1 & & 147.484 \\
\hline & $\mathrm{T} / \mathrm{T}$ & $0.625(0.115-3.298)$ & 0.586 & \\
\hline \multirow{2}{*}{ Overdominant } & $\mathrm{T} / \mathrm{T}+\mathrm{C} / \mathrm{C}$ & 1 & & 147.762 \\
\hline & $\mathrm{T} / \mathrm{C}$ & $1.001(0.424-2.362)$ & 0.998 & \\
\hline Additive & - & $0.870(0.441-1.717)$ & 0.688 & 147.603 \\
\hline \multicolumn{5}{|l|}{ Females } \\
\hline \multirow{3}{*}{ Codominant } & CC & 1 & & 271.981 \\
\hline & $\mathrm{CT}$ & $0.528(0.284-0.981)$ & 0.043 & \\
\hline & $\mathrm{TT}$ & $1.033(0.278-3.837)$ & 0.961 & \\
\hline \multirow{2}{*}{ Dominant } & CC & 1 & & 269.092 \\
\hline & $\mathrm{T} / \mathrm{C}+\mathrm{T} / \mathrm{T}$ & $0.579(0.318-1.053)$ & 0.073 & \\
\hline \multirow{2}{*}{ Recessive } & $\mathrm{C} / \mathrm{C}+\mathrm{C} / \mathrm{T}$ & 1 & & 272.068 \\
\hline & $\mathrm{T} / \mathrm{T}$ & $1.368(0.382-4.907)$ & 0.630 & \\
\hline \multirow{2}{*}{ Overdominant } & $\mathrm{T} / \mathrm{T}+\mathrm{C} / \mathrm{C}$ & 1 & & 267.927 \\
\hline & $\mathrm{T} / \mathrm{C}$ & $0.526(0.288-0.961)$ & 0.037 & \\
\hline Additive & - & $0.748(0.471-1.187)$ & 0.218 & 270.822 \\
\hline
\end{tabular}

TABLE 6: Frequency of MMP-2 (-1306 C/T) genotype in the patients with pituitary adenoma (PA) and in the control group by PA invasiveness.

\begin{tabular}{|c|c|c|c|c|c|c|c|}
\hline \multirow[b]{2}{*}{ Gene marker } & \multirow[b]{2}{*}{ Genotype/allele } & \multicolumn{6}{|c|}{ Frequency (\%) } \\
\hline & & $\begin{array}{c}\text { Control group } \\
n(\%) \\
(n=318) \\
\end{array}$ & $\stackrel{p}{\mathrm{HWE}}$ & $\begin{array}{c}\text { Noninvasive PA group } \\
n(\%) \\
(n=37) \\
\end{array}$ & $\underset{\mathrm{HWE}}{p}$ & $\begin{array}{c}\text { Invasive PA group } \\
n(\%) \\
(n=47) \\
\end{array}$ & $\stackrel{p}{\mathrm{HWE}}$ \\
\hline \multirow{8}{*}{$\begin{array}{l}M M P-2 \\
(-1306) \\
\text { Rs } 243865\end{array}$} & Genotype & & \multirow{8}{*}{0.383} & & \multirow{8}{*}{0.064} & & \multirow{8}{*}{0.5823} \\
\hline & $\mathrm{C} / \mathrm{C}$ & $190^{*}(59.75)$ & & $13^{*}(35.1)$ & & $29(61.7)$ & \\
\hline & $\mathrm{C} / \mathrm{T}$ & $108^{* *}(33.96)$ & & $22^{* *}(59.5)$ & & $15(31.9)$ & \\
\hline & $\mathrm{T} / \mathrm{T}$ & $20(6.29)$ & & $2(5.4)$ & & $3(6.4)$ & \\
\hline & Total & $318(100)$ & & 37 (100) & & 47 (100) & \\
\hline & Allele & & & & & & \\
\hline & $\mathrm{C}$ & $488(76.72)$ & & $48(64.86)$ & & $73(77.66)$ & \\
\hline & $\mathrm{T}$ & $148(23.33)$ & & $26(35.14)$ & & $21(22.34)$ & \\
\hline
\end{tabular}

${ }^{*} p=0.0049$.

${ }^{* *} p=0.0035$.

MMP: matrix metalloproteinase; $p$ value: significance level (alfa $=0.05$ ); $p$-value HWE: significance level $(\mathrm{alfa}=0.05)$ by Hardy-Weinberg equilibrium.

basis of these findings, we sought to examine whether the polymorphism in the MMP2 (-1306) promoter could have an impact on the risk of PA development. We analyzed $84 \mathrm{PA}$ patients and 318 age- and sex-matched controls for the $-1306 \mathrm{C} / \mathrm{T}$ polymorphism in the $M M P-2$ promoter. Our results demonstrated that $M M P-2(-1306 C / T)$ gene polymorphism has not revealed any differences in the genotype $(C / C, C / T$, and $T / T)$ distribution between the PA patients and the reference group (as follows: 50\%, 44\%, and 6\% versus $59.75 \%, 33.96 \%$, and $6.29 \%)$, but $M M P-2(-1306) C / T$ genotype was more frequently present in PA females compared to healthy controls females: $49.1 \%$ versus $33.66 \%$; $p=0.041$.

To our knowledge, there are no studies which have explored the relationship between the polymorphisms in MMP2 $-1306 \mathrm{C} / \mathrm{T}$ and the development of PA. However, several studies have analyzed MMP-2 expression in PA [5, 39, 40]. Liu et al. [39] have found that the MMP-2 score of PAs with cavernous sinus invasion $(3.9 \pm 0.5)$ was significantly higher than those without invasion $(2.3 \pm 0.2 ; p<$ 0.01 ). There was no difference in the MMP-2 score between macroadenomas $(3.0 \pm 0.3)$ and microadenomas $(2.1 \pm 0.4$; 
TABLE 7: Frequency of MMP-2 (-1306 C/T) genotype in the patients with pituitary adenoma (PA) and in the control group by PA recurrences.

\begin{tabular}{|c|c|c|c|c|c|c|c|}
\hline \multirow[b]{2}{*}{ Gene marke } & \multirow[b]{2}{*}{ Genotype/allele } & \multicolumn{6}{|c|}{ Frequency (\%) } \\
\hline & & $\begin{array}{c}\text { Control group } \\
n(\%) \\
(n=318)\end{array}$ & $\begin{array}{c}p \\
\text { HWE }\end{array}$ & $\begin{array}{c}\text { Nonrecurrence PA group } \\
n(\%) \\
(n=71)\end{array}$ & $\stackrel{p}{\mathrm{HWE}}$ & $\begin{array}{c}\text { Recurrence PA group } \\
n(\%) \\
(n=13)\end{array}$ & $\underset{\mathrm{HWE}}{p}$ \\
\hline \multirow{8}{*}{$\begin{array}{l}\text { MMP-2 } \\
(-1306) \\
\text { Rs } 243865\end{array}$} & Genotype & & \multirow{8}{*}{0.383} & & \multirow{5}{*}{0.3958} & & \multirow{8}{*}{0.5121} \\
\hline & $\mathrm{C} / \mathrm{C}$ & $190^{*}(59.75)$ & & $33^{*}(46.5)$ & & $9(69.2)$ & \\
\hline & $\mathrm{C} / \mathrm{T}$ & $108(33.96)$ & & $33(46.5)$ & & $4(30.8)$ & \\
\hline & $\mathrm{T} / \mathrm{T}$ & $20(6.29)$ & & $5(7.0)$ & & $0(0)$ & \\
\hline & Total & $318(100)$ & & $71(100)$ & & $13(100)$ & \\
\hline & \multicolumn{5}{|l|}{ Allele } & & \\
\hline & C & $488(76.72)$ & & $99(69.72)$ & & $22(84.62)$ & \\
\hline & $\mathrm{T}$ & $148(23.33)$ & & $43(30.28)$ & & $4(15.38)$ & \\
\hline
\end{tabular}

${ }^{*} p=0.0468$.

MMP: matrix metalloproteinase; $p$ value: significance level (alfa $=0.05$ ); $p$-value HWE: significance level (alfa $=0.05)$ by Hardy-Weinberg equilibrium.

TABLE 8: Binomial logistic regression analysis in noninvasive and nonrecurrence pituitary adenoma (PA) and in the control group.

\begin{tabular}{|c|c|c|c|c|}
\hline Model & Genotype & OR (CI 95\%) & $p$ value & AIC \\
\hline \multicolumn{5}{|l|}{ Noninvasive } \\
\hline \multirow{3}{*}{ Codominant } & $\mathrm{CC}$ & 1 & & 234.221 \\
\hline & $\mathrm{CT}$ & $2.977(1.442-6.148)$ & 0.003 & \\
\hline & $\mathrm{TT}$ & $1.462(0.308-6.944)$ & 0.633 & \\
\hline \multirow{2}{*}{ Dominant } & $\mathrm{CC}$ & 1 & & 233.197 \\
\hline & $\mathrm{T} / \mathrm{C}+\mathrm{T} / \mathrm{T}$ & $2.740(1.346-5.581)$ & 0.005 & \\
\hline \multirow{2}{*}{ Recessive } & $\mathrm{C} / \mathrm{C}+\mathrm{C} / \mathrm{T}$ & 1 & & 241.285 \\
\hline & $\mathrm{T} / \mathrm{T}$ & $0.851(0.191-3.797)$ & 0.833 & \\
\hline \multirow{2}{*}{ Overdominant } & $\mathrm{T} / \mathrm{T}+\mathrm{C} / \mathrm{C}$ & 1 & & 232.431 \\
\hline & $\mathrm{T} / \mathrm{C}$ & $2.852(1.422-5.721)$ & 0.003 & \\
\hline Additive & - & $1.782(1.065-2.982)$ & 0.028 & 236.667 \\
\hline \multicolumn{5}{|l|}{ Nonrecurrence } \\
\hline \multirow{3}{*}{ Codominant } & $\mathrm{CC}$ & 1 & & 371.421 \\
\hline & $\mathrm{CT}$ & $1.759(1.028-3.011)$ & 0.039 & \\
\hline & $\mathrm{TT}$ & $1.439(0.505-4.102)$ & 0.496 & \\
\hline \multirow{2}{*}{ Dominant } & $\mathrm{CC}$ & 1 & & 369.564 \\
\hline & $\mathrm{T} / \mathrm{C}+\mathrm{T} / \mathrm{T}$ & $1.709(1.019-2.868)$ & 0.042 & \\
\hline \multirow{2}{*}{ Recessive } & $\mathrm{C} / \mathrm{C}+\mathrm{C} / \mathrm{T}$ & 1 & & 373.646 \\
\hline & $\mathrm{T} / \mathrm{T}$ & $1.129(0.409-3.117)$ & 0.815 & \\
\hline \multirow{2}{*}{ Overdominant } & $\mathrm{T} / \mathrm{T}+\mathrm{C} / \mathrm{C}$ & 1 & & 369.859 \\
\hline & $\mathrm{T} / \mathrm{C}$ & $1.689(1.003-2.843)$ & 0.049 & \\
\hline Additive & - & $1.423(0.953-2.123)$ & 0.084 & 370.788 \\
\hline
\end{tabular}

$p>0.05)$, and also no difference between the functioning adenomas $(2.8 \pm 0.3)$ and nonfunctioning adenomas $(2.8 \pm$ $0.3 ; p>0.05$ ) [5]. MMP-2 mRNA expression was also intense in invasive pituitary adenomas and was significantly higher in invasive pituitary adenomas than those without invasion $(68.2 \pm 15.3 ; 21.8 \pm 8.2 ; p<0.05)$. Pereda et al. [40] have observed the activities of MMP-2 and MMP-9 together with the expression of membrane-type MMP and tissue inhibitor of metalloproteinase- 1 in all types of human pituitary adenomas. They found high levels of MMP activity and low levels of tissue inhibitor of metalloproteinases, indicating a high level of extracellular matrix-degrading activity in PAs.
Numerous studies have demonstrated overexpressed MMP-2 in various tumours: breast cancer [22-27], lung cancer [28], colorectal tumours [29], gastric and esophageal cancers [31-35], and pancreatic carcinoma [30]. Some studies have reported the expression of MMP-2 in human gliomas [36-38].

Numerous studies have also been carried out to look for an association between the MMP-2 -1306 C/T polymorphism and risk of other human tumours, but the results remain controversial [49-61].

$\mathrm{Yu}$ et al. [49] in their research have found that the allele frequency of $M M P 2-1306 \mathrm{C}$ was significantly higher among cases of lung cancer than among controls ( 0.91 versus 
0.83). Subjects with the CC genotype had an overall 2fold increased risk of developing lung cancer [adjusted OR 2.18; 95\% confidence interval (CI), 1.70-2.79] compared with those with the CT or TT genotype. In another study $\mathrm{Yu}$ et al. [55] have reported that the $\mathrm{C}_{-1306}-\mathrm{C}_{-735}$ haplotype in the $M M P-2$ promoter contributes to risk of the occurrence and metastasis of esophageal squamous cell carcinoma by increasing the expression of MMP-2. In another study this group of researches has found that subjects with the $C C$ genotype had a more than 3-fold increased risk [adjusted OR 3.36, 95\% confidence interval 2.34-4.97] for developing gastric cardia adenocarcinoma compared with those with the variant CT or TT genotype. The increased risk was found to be more pronounced in smokers and younger subjects. No significant association was demonstrated between the $M M P 2$ polymorphism and the risk of metastasis of the cancer at the time of diagnosis, with the OR being 0.90 (95\% confidence interval $0.36-2.20$ ) for the CC genotype [50]. In breast cancer research Miao et al. [50] have found that the variant MMP2 genotype (-1306 CT or TT) was associated with substantially reduced risk of breast cancer [OR $0.46 ; 95 \%$ confidence interval (95\% CI), 0.34-0.63], compared with the CC genotype. Grieu et al. [62] have also reported that MMP2 TT homozygous patients had smaller breast tumours $(p=$ $0.006)$ and contained lower concentrations of the estrogen receptor $(\mathrm{ER} ; p=0.002)$ compared to patients with the MMP-2 CC or CT genotype. Homozygosity for the MMP-2 $-1306 \mathrm{~T}$ allele was associated with markedly different patient survival depending upon tumour ER status. For patients with ER negative tumours, the MMP-2 TT genotype was associated with poor survival (2/8 patients alive at end of study, 25\%) compared to the CC or CT genotypes (59/70, 84\%; $p<0.001)$. For patients with ER positive tumours, the MMP-2 TT genotype was associated with a trend for very good survival $(10 / 10,100 \%)$ compared to the CC or CT genotypes $(130 / 157,83 \% ; p=0.16)$.

Lin et al. in their study [52] provided evidence that $-1306 C \rightarrow T$ polymorphism in the MMP-2 promoter is a susceptibility factor for the development of oral squamous cell carcinoma, with the $C C$ genotype being associated with the increase of risk. O-charoenrat and Khantapura [58] have reported that subjects with the MMP2 CC genotype were associated with a significantly increased risk [adjusted OR 1.97; 95\% confidence interval (95\% CI), 1.23-3.15] for developing HNSCC compared with those with the variant genotype (-1306 CT or TT).

$\mathrm{Xu}$ et al. [60] have found that the frequency of MMP2 CC genotype was significantly higher in colorectal cancer patients when compared with controls (OR, 1.959; 95\% CI, 1.055-3.637). Srivastava et al. [61] have found that patients with MMP2 (-1306) CT genotype as well as T allele were at higher risk of prostate cancer $(p=0.018$; OR $=1.68$ and $p=0.015 ; \mathrm{OR}=1.52)$. This effect was even more evident in the case of the T allele carrier $(\mathrm{CT}+\mathrm{TT})(p=0.011 ; \mathrm{OR}=1.71)$. Shao et al. [63] have reported that the risk of nasopharyngeal carcinoma was significantly increased in young ( $<60$ years) subjects with the $-1306 \mathrm{CC}$ genotype $(\mathrm{OR}=1.52,95 \% \mathrm{CI}=$ 1.01-2.29). Wieczorek et al. [56] have found that the combined genotype MMP2 -1306 C/T (rs243865) allele T with MMP9
$-1562 \mathrm{C} / \mathrm{T}$ (rs3918242) allele $\mathrm{T}$ increased bladder cancer risk (OR 2.00, 95\% CI 1.10-3.62; $p=0.022$ ).

On the basis of these findings, we hypothesized that the $-1306 \mathrm{C} / \mathrm{T}$ polymorphism in MMP-2 might also have impact on individual susceptibility to PA.

Some authors have not found an association of MMP-2 $(-1306 \mathrm{C} / \mathrm{T})$ polymorphism with tumours. Rollin et al. [53] have found no difference in $-1306 \mathrm{C} / \mathrm{T}$ MMP-2, $-735 \mathrm{C} / \mathrm{T}$ MMP-2, and -1562 C/T MMP-9 genotypes between cases of non-small cell lung cancer and controls. Eftekhary et al. [54] have found no statistically significant differences in genotype and allele frequencies of MMP-2 (-1306 C/T) between patients with esophageal squamous cell carcinoma and controls $(p>0.05)$. A significant association of the MMP-2 (-1306 C/T) polymorphism with GBM $(p=0.475)$ was not found by Kumar et al. [59] suggesting that MMP-2 $(-1306 \mathrm{C} / \mathrm{T})$ polymorphism is not associated with increased GBM susceptibility. Kawal et al. [57] have not found a significant association of MMP-2 (-1306 C/T) polymorphism with oligodendroglioma $(p=0.54)$.

To the best of our knowledge, this is the first study to examine the relationship between the $M M P-2(-1306 \mathrm{C} / \mathrm{T})$ polymorphism and PA risk. Our study showed a significantly greater prevalence of the $\mathrm{C} / \mathrm{T}$ genotype in females than their control counterparts. Further studies with a larger number of patients, however, are necessary in order to better understand the real value of such a normative database in developing of PA.

Our study suggests that the effects of polymorphisms of $M M P s$ on PA risk deserve further investigation.

\section{Competing Interests}

The authors declare that they have no competing interests.

\section{Acknowledgments}

The authors thank Silvija Jakstiene for radiological evaluation and Professor Abdonas Tamosiunas for control group data. This study was supported by Lithuanian Science Council (Grant no. MIP-008/2014) and the Wellcome Trust (Grant no. 064947/Z/01/Z); the US National Institute on Aging (Grant no. IR0I AG23522-01), the MacArthur Foundation (Health and Social Upheaval network); Oslo University College (Grant no. 57116).

\section{References}

[1] R. B. Page, "Sellar and parasellar tumors," in Neurosurgery, R. H. Wilkins and S. S. Rengachary, Eds., pp. 791-804, McGraw-Hill, 2nd edition, 1996.

[2] S. Ezzat, S. L. Asa, W. T. Couldwell et al., "The prevalence of pituitary adenomas," Cancer, vol. 101, no. 3, pp. 613-619, 2004.

[3] C. Destrieux, M. K. Kakou, S. Velut, T. Lefrancq, and M. Jan, "Microanatomy of the hypophyseal fossa boundaries," Journal of Neurosurgery, vol. 88, no. 4, pp. 743-752, 1998.

[4] A. Colao, C. Di Somma, R. Pivonello, A. Faggiano, G. Lombardi, and S. Savastano, "Medical therapy for clinically nonfunctioning pituitary adenomas," Endocrine-Related Cancer, vol. 15, no. 4, pp. 905-915, 2008. 
[5] R. Kasputytė, G. Slatkevičienè, R. Liutkevičienè, B. Glebauskienè, G. Bernotas, and A. Tamašauskas, "Changes of visual functions in patients with pituitary adenoma," Medicina (Kaunas), vol. 49, no. 3, pp. 132-137, 2013.

[6] R. Thomas, K. Shenoy, M. S. Seshadri, J. Muliyil, A. Rao, and P. Paul, "Visual field defects in non-functioning pituitary adenomas," Indian Journal of Ophthalmology, vol. 50, no. 2, pp. 127-130, 2002.

[7] E. Ferrante, M. Ferraroni, T. Castrignanò et al., "Nonfunctioning pituitary adenoma database: a useful resource to improve the clinical management of pituitary tumors," European Journal of Endocrinology, vol. 155, no. 6, pp. 823-829, 2006.

[8] J. Ahmadi, C. M. North, H. D. Segall, C. S. Zee, and M. H. Weiss, "Cavernous sinus invasion by pituitary adenomas," American Journal of Neuroradiology, vol. 6, no. 6, pp. 893-898, 1985.

[9] R. Fahlbusch and M. Buchfelder, "Transsphenoidal surgery of parasellar pituitary adenomas," Acta Neurochirurgica, vol. 92, no. 1-4, pp. 93-99, 1988.

[10] S. Ezzat and S. L. Asa, "Mechanisms of disease: the pathogenesis of pituitary tumors," Nature Clinical Practice Endocrinology and Metabolism, vol. 2, no. 4, pp. 220-230, 2006.

[11] M. Mareel and A. Leroy, "Clinical, cellular, and molecular aspects of cancer invasion," Physiological Reviews, vol. 83, no. 2, pp. 337-376, 2003.

[12] B. M. Fingleton, K. J. Heppner Goss, H. C. Crawford, and L. M. Matrisian, "Matrilysin in early stage intestinal tumorigenesis," APMIS, vol. 107, no. 1, pp. 102-110, 1999.

[13] I. Stamenkovic, "Matrix metalloproteinases in tumor invasion and metastasis," Seminars in Cancer Biology, vol. 10, no. 6, pp. 415-433, 2000.

[14] S. Chakraborti, M. Mandal, S. Das, A. Mandal, and T. Chakraborti, "Regulation of matrix metalloproteinases: an overview," Molecular and Cellular Biochemistry, vol. 253, no. 1-2, pp. 269-285, 2003.

[15] H. Nagaset and J. F. Woessner Jr., "Matrix metalloproteinases," The Journal of Biological Chemistry, vol. 274, no. 31, pp. 2149121494, 1999.

[16] N. Johansson, M. Ahonen, and V.-M. Kähäri, "Matrix metalloproteinases in tumor invasion," Cellular and Molecular Life Sciences, vol. 57, no. 1, pp. 5-15, 2000.

[17] S. Curran and G. I. Murray, "Matrix metalloproteinases in tumour invasion and metastasis," The Journal of Pathology, vol. 189, no. 3, pp. 300-308, 1999.

[18] V.-M. Kähäri and U. Saarialho-Kere, "Matrix metalloproteinases and their inhibitors in tumour growth and invasion," Annals of Medicine, vol. 31, no. 1, pp. 34-45, 1999.

[19] J. Westermarck and V.-M. Kähäri, "Regulation of matrix metalloproteinase expression in tumor invasion," FASEB Journal, vol. 13, no. 8, pp. 781-792, 1999.

[20] M. Egeblad and Z. Werb, "New functions for the matrix metalloproteinases in cancer progression," Nature Reviews Cancer, vol. 2, no. 3, pp. 161-174, 2002.

[21] L. J. McCawley and L. M. Matrisian, "Matrix metalloproteinases: they're not just for matrix anymore!," Current Opinion in Cell Biology, vol. 13, no. 5, pp. 534-540, 2001.

[22] J. L. Jones, P. Glynn, and R. A. Walker, "Expression of MMP-2 and MMP-9, their inhibitors, and the activator MT1-MMP in primary breast carcinomas," The Journal of Pathology, vol. 189, pp. 161-168, 1999.

[23] E. A. Garbett, M. W. R. Reed, and N. J. Brown, "Proteolysis in human breast and colorectal cancer," British Journal of Cancer, vol. 81, no. 2, pp. 287-293, 1999.
[24] O. Brummer, S. Athar, L. Riethdorf, T. Löning, and H. Herbst, "Matrix-metalloproteinases 1, 2 and 3 and their tissue inhibitors 1 and 2 in benign and malignant breast lesions: an in situ hybridization study," Virchows Archiv, vol. 435, no. 6, pp. 566573, 1999.

[25] E. A. Baker, T. J. Stephenson, M. W. R. Reed, and N. J. Brown, "Expression of proteinases and inhibitors in human breast cancer progression and survival," Molecular Pathology, vol. 55, no. 5, pp. 300-304, 2002.

[26] B. Davies, D. W. Miles, L. C. Happerfield et al., "Activity of type IV collagenases in benign and malignant breast disease," British Journal of Cancer, vol. 67, no. 5, pp. 1126-1131, 1993.

[27] K.-W. Min, D.-H. Kim, S.-I. Do et al., "Expression patterns of stromal MMP-2 and tumoural MMP-2 and -9 are significant prognostic factors in invasive ductal carcinoma of the breast," APMIS: Acta Pathologica, Microbiologica, et Immunologica Scandinavica, vol. 122, no. 12, pp. 1196-1206, 2014.

[28] T. Leinonen, R. Pirinen, J. Böhm, R. Johansson, and V.-M. Kosma, "Increased expression of matrix metalloproteinase-2 (MMP-2) predicts tumour recurrence and unfavourable outcome in non-small cell lung cancer," Histology and Histopathology, vol. 23, no. 6, pp. 693-700, 2008.

[29] Z.-S. Zeng, A. M. Cohen, and J. G. Guillem, "Loss of basement membrane type IV collagen is associated with increased expression of metalloproteinases 2 and 9 (MMP-2 and MMP-9) during human colorectal tumorigenesis," Carcinogenesis, vol. 20, no. 5, pp. 749-755, 1999.

[30] Y. L. Gong, G. M. Xu, W. D. Huang, and L. B. Chen, "Expression of matrix metalloproteinases and the tissue inhibitors of metalloproteinases and their local invasiveness and metastasis in Chinese human pancreatic cancer," Journal of Surgical Oncology, vol. 73, no. 2, pp. 95-99, 2000.

[31] H. L. Wang, P. Y. Zhou, Y. Zhang, and P. Liu, "Relationships between abnormal MMP2 expression and prognosis in gastric cancer: a meta-analysis of cohort studies," Cancer Biotherapy and Radiopharmaceuticals, vol. 29, no. 4, pp. 166-172, 2014.

[32] S. de la Peña, C. L. Sampieri, M. Ochoa-Lara, K. León-Córdoba, and J. M. Remes-Troche, "Expression of the matrix metalloproteases $2,14,24$, and 25 and tissue inhibitor 3 as potential molecular markers in advanced human gastric cancer," Disease Markers, vol. 2014, Article ID 285906, 9 pages, 2014.

[33] H. Koyama, H. Iwata, Y. Kuwabara, H. Iwase, S. Kobayashi, and Y. Y. Fujii, "Gelatinolytic activity of matrix metalloproteinase2 and -9 in oesophageal carcinoma; A study using in situ zymography," European Journal of Cancer, vol. 36, no. 16, pp. 2164-2170, 2000.

[34] S. P. Mönig, S. E. Baldus, J. K. Hennecken et al., "Expression of MMP-2 is associated with progression and lymph node metastasis of gastric carcinoma," Histopathology, vol. 39, no. 6, pp. 597-602, 2001.

[35] H. Nomura, N. Fujimoto, M. Seiki, M. Mai, and Y. Okada, "Enhanced production of matrix metalloproteinases and activation of matrix metalloproteinase 2 (gelatinase A) in human gastric carcinomas," International Journal of Cancer, vol. 69, no. 1, pp. 9-16, 1996.

[36] M. Yamamoto, S. Mohanam, R. Sawaya et al., "Differential expression of membrane-type matrix metalloproteinase and its correlation with gelatinase A activation in human malignant brain tumors in vivo and in vitro," Cancer Research, vol. 56, no. 2, pp. 384-392, 1996.

[37] T. Nakagawa, T. Kubota, M. Kabuto et al., "Production of matrix metalloproteinases and tissue inhibitor of metalloproteinases-1 
by human brain tumors," Journal of Neurosurgery, vol. 81, no. 1, pp. 69-77, 1994.

[38] R. E. Sawaya, M. Yamamoto, Z. L. Gokaslan et al., "Expression and localization of $72 \mathrm{kDa}$ type IV collagenase (MMP-2) in human malignant gliomas in vivo," Clinical \& Experimental Metastasis, vol. 14, no. 1, pp. 35-42, 1996.

[39] W. Liu, Y. Matsumoto, M. Okada et al., "Matrix metalloproteinase 2 and 9 expression correlated with cavernous sinus invasion of pituitary adenomas," Journal of Medical Investigation, vol. 52, no. 3-4, pp. 151-158, 2005.

[40] M. P. Pereda, M. F. Ledda, V. Goldberg et al., "High levels of matrix metalloproteinases regulate proliferation and hormone secretion in pituitary cells," Journal of Clinical Endocrinology and Metabolism, vol. 85, no. 1, pp. 263-269, 2000.

[41] S. Ye, "Polymorphism in matrix metalloproteinase gene promoters: implication in regulation of gene expression and susceptibility of various diseases," Matrix Biology, vol. 19, no. 7, pp. 623-629, 2000.

[42] S. J. Price, D. R. Greaves, and H. Watkins, "Identification of novel, functional genetic variants in the human matrix metalloproteinase- 2 gene. Role of Sp1 in allele-specific transcriptional regulation," Journal of Biological Chemistry, vol. 276, no. 10, pp. 7549-7558, 2001.

[43] V. Vašků, A. Vašků, S. Tschöplová, L. Izakovičová Hollá, V. Semrádová, and J. Vácha, "Genotype association of $\mathrm{C}(-735) \mathrm{T}$ polymorphism in matrix metalloproteinase 2 gene with G(8002)A endothelin 1 gene with plaque psoriasis," Dermatology, vol. 204, no. 4, pp. 262-265, 2002.

[44] S. Haque, N. Akhter, M. Lohani, A. Ali, and R. K. Mandal, "Matrix metalloproteinase-2 $-1306 \mathrm{C}>\mathrm{T}$ gene polymorphism is associated with reduced risk of cancer: a meta-analysis," Asian Pacific Journal of Cancer Prevention, vol. 16, no. 3, pp. 889-896, 2015.

[45] B. Peng, L. Cao, X. Ma, W. Wang, D. Wang, and L. Yu, "Metaanalysis of association between matrix metalloproteinases 2, 7 and 9 promoter polymorphisms and cancer risk," Mutagenesis, vol. 25, no. 4, pp. 371-379, 2010.

[46] C. B. Wilson, "Neurosurgical management of large and invasive pituitary tumors," in Clinical Management of Pituitary Disorders, G. T. Tindall and W. F. Collins, Eds., pp. 335-342, Raven Press, New York, NY, USA, 1979.

[47] E. Knosp, E. Steiner, K. Kitz, and C. Matula, "Pituitary adenomas with invasion of the cavernous sinus space: a magnetic resonance imaging classification compared with surgical findings," Neurosurgery, vol. 33, pp. 610-617, 1993.

[48] A. Heaney, "Management of aggressive pituitary adenomas and pituitary carcinomas," Journal of Neuro-Oncology, vol. 117, no. 3 , pp. 459-468, 2014.

[49] C. Yu, K. Pan, D. Xing et al., "Correlation between a single nucleotide polymorphism in the matrix metalloproteinase-2 promoter and risk of lung cancer," Cancer Research, vol. 62, no. 22, pp. 6430-6433, 2002.

[50] X. Miao, C. Yu, W. Tan et al., "A functional polymorphism in the matrix metalloproteinase-2 gene promoter $(-1306 \mathrm{C} / \mathrm{T})$ is associated with risk of development but not metastasis of gastric cardia adenocarcinoma," Cancer Research, vol. 63, no. 14, pp. 3987-3990, 2002.

[51] Y. Zhou, C. Yu, X. Miao et al., "Substantial reduction in risk of breast cancer associated with genetic polymorphisms in the promoters of the matrix metalloproteinase-2 and tissue inhibitor of metalloproteinase-2 genes," Carcinogenesis, vol. 25, no. 3, pp. 399-404, 2004.
[52] S.-C. Lin, S.-S. Lo, C.-J. Liu, M.-Y. Chung, J.-W. Huang, and K.W. Chang, "Functional genotype in matrix metalloproteinases-2 promoter is a risk factor for oral carcinogenesis," Journal of Oral Pathology \& Medicine, vol. 33, no. 7, pp. 405-409, 2004.

[53] J. Rollin, S. Régina, P. Vourc'h et al., "Influence of MMP-2 and MMP-9 promoter polymorphisms on gene expression and clinical outcome of non-small cell lung cancer," Lung Cancer, vol. 56, no. 2, pp. 273-280, 2007.

[54] H. Eftekhary, A. A. Ziaee, M. Yazdanbod, M. Shahpanah, A. Setayeshgar, and M. Nassiri, "The influence of matrix metalloproteinase- $2,-9$, and -12 promoter polymorphisms on Iranian patients with oesophageal squamous cell carcinoma," Contemporary Oncology (Poznan), vol. 19, no. 4, pp. 300-305, 2015.

[55] C. Yu, Y. Zhou, X. Miao, P. Xiong, W. Tan, and D. X. Lin, "Functional haplotypes in the promoter of matrix metalloproteinase2 predict risk of the occurrence and metastasis of esophageal cancer," Cancer Research, vol. 64, no. 20, pp. 7622-7628, 2004.

[56] E. Wieczorek, E. Reszka, Z. Jablonowski et al., "Genetic polymorphisms in matrix metalloproteinases (MMPs) and tissue inhibitors of MPs (TIMPs), and bladder cancer susceptibility," BJU International, vol. 112, no. 8, pp. 1207-1214, 2013.

[57] P. Kawal, A. Chandra, Rajkumar, T. N. Dhole, and B. Ojha, "Correlations of polymorphisms in matrix metalloproteinase$1,-2$, and -7 promoters to susceptibility to malignant gliomas," Asian Journal of Neurosurgery, vol. 11, no. 2, pp. 160-166, 2016.

[58] P. O-charoenrat and P. Khantapura, "The role of genetic polymorphisms in the promoters of the matrix metalloproteinase-2 and tissue inhibitor of metalloproteinase-2 genes in head and neck cancer," Oral Oncology, vol. 42, no. 3, pp. 257-267, 2006.

[59] R. Kumar, N. Malik, A. Tungaria, and P. Kawal, "Matrix metalloproteinase-2 gene polymorphism is not associated with increased glioblastoma multiforme susceptibility: an Indian institutional experience," Neurology India, vol. 59, no. 2, pp. 236-240, 2011.

[60] E. Xu, M. Lai, B. Lv, X. Xing, Q. Huang, and X. Xia, "A single nucleotide polymorphism in the matrix metalloproteinase-2 promoter is associated with colorectal cancer," Biochemical and Biophysical Research Communications, vol. 324, no. 3, pp. 9991003, 2004.

[61] P. Srivastava, T. A. Lone, R. Kapoor, and R. D. Mittal, “Association of promoter polymorphisms in MMP2 and TIMP2 with prostate cancer susceptibility in North India," Archives of Medical Research, vol. 43, no. 2, pp. 117-124, 2012.

[62] F. Grieu, W. Q. Li, and B. Iacopetta, "Genetic polymorphisms in the MMP-2 and MMP-9 genes and breast cancer phenotype," Breast Cancer Research and Treatment, vol. 88, no. 3, pp. 197204, 2004.

[63] J.-Y. Shao, Y. Cao, X.-P. Miao et al., "A single nucleotide polymorphism in the matrix metalloproteinase 2 promoter is closely associated with high risk of nasopharyngeal carcinoma in Cantonese from southern China," Chinese Journal of Cancer, vol. 30, no. 9, pp. 620-626, 2011. 

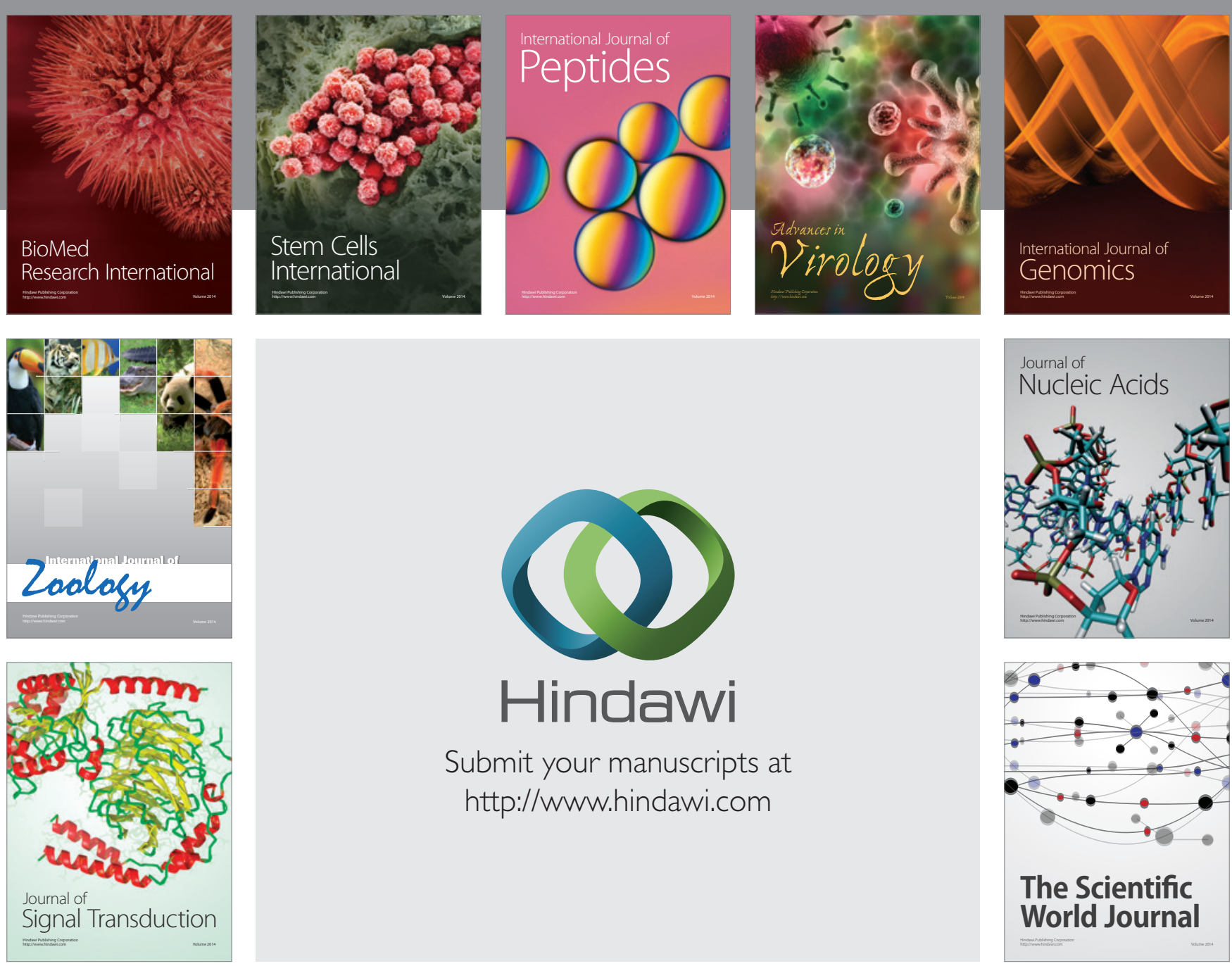

Submit your manuscripts at

http://www.hindawi.com
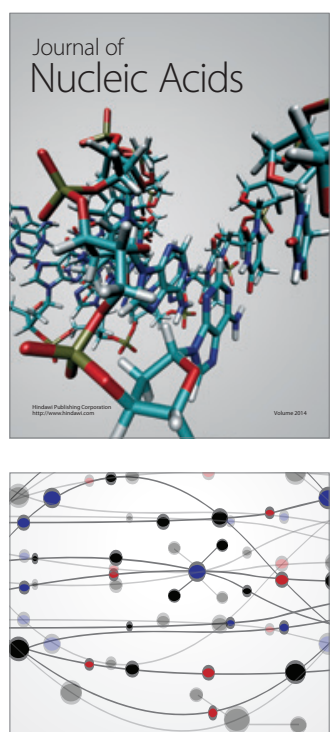

The Scientific World Journal
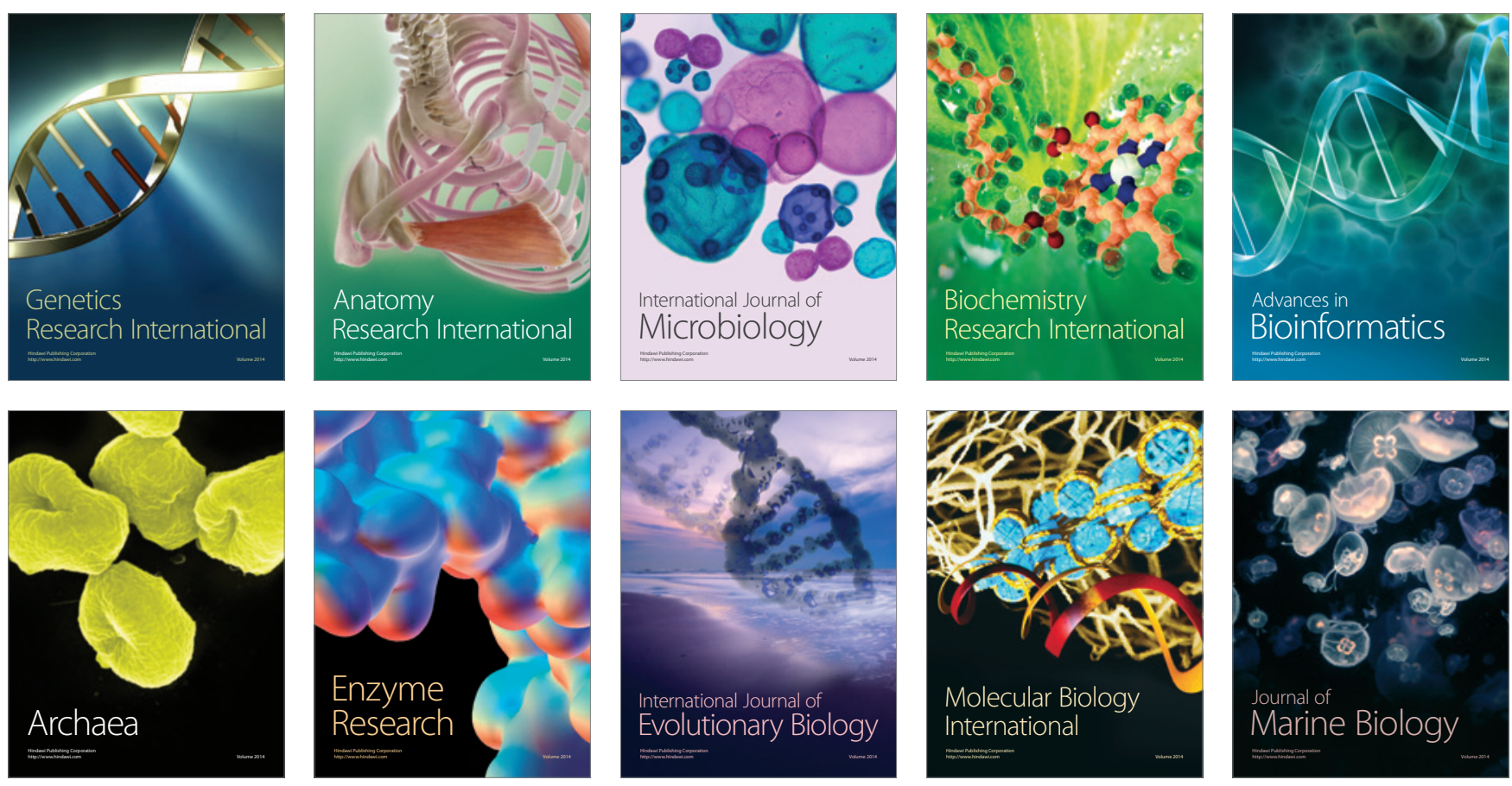